\title{
OPTIMUM CONDITION FOR STABILTY OF AN ARTIFICIAL BEACH WITH A GRAVEL FILTER LAYER UNDER IRREGULAR WAVE ACTION
}

\author{
Gozo Tsujimoto ${ }^{1}$,Tokuzo Hosoyamada ${ }^{2}$ and Tetsuya Kakinoki
}

\begin{abstract}
The safety of a fail-safe artificial beach was studied. Beach profile changes and the onshore-offshore distribution of the sand particle size were measured in a water flume. Under the action of erosive waves, sand particles are deposited on the run-up area. Because of the increasing permeability of the filter layer, the beach profile can be in equilibrium. A filter layer promotes the sorting of sand particles, and depositional waves deposit coarse sediments on the onshore side and fine sediments on the offshore side for an erosive-type beach. A filter layer has the potential to change the beach profile without requiring changes in the water level. The permeability of a filter layer has greater effect on the water velocities and water surface in the stage of run- down than in the stage of run-up.
\end{abstract}

Keywords: sediment transport; numerical simulation; change in water level; digital image;

\section{Introduction}

A filter layer has been used to prevent serious accidents at an artificial beach in response to the sinking of the beach surface. A filter layer generally has a constant installation depth relative the beach surface although its scale differs depending on the natural conditions of the beach. The sand grain size of an artificial beach with a filter layer is greater than that of a natural beach, and subsequently the beach becomes a mixed-sand beach with gravel or cobble. Few design methods are currently available for an artificial beach with a filter layer. With this background, the changes in the beach profiles has been studied under regular wave actions with changing filter-layer conditions of the coefficient of permeability and installation depth.(Tsujimoto at al.2007; hereafter referred to as the former paper).

The objectives of this paper are to propose optimum conditions for the stability of an artificial beach under the influence of irregular wave action on the basis of the experimental results of the former paper, to examine the invertibility of the beach in terms of sand grain size using digital images and to develop a numerical approach for flow fields.

\section{Laboratory procedure}

\subsection{Experimental apparatus}

Experiments were conducted in an $18 \mathrm{~m}$ long, $0.8 \mathrm{~m}$ deep and $0.6 \mathrm{~m}$ wide water flume at the Kobe City College of Technology. At the end of the flume, there were movable beds with 1:10 slopes made of sand with a medium size of $0.5 \mathrm{~mm}$ and coefficient of permeability of $0.14 \mathrm{~cm} / \mathrm{s}$. A filter layer of $1 \mathrm{~m}$ in length, $0.6 \mathrm{~m}$ in width and $0.1 \mathrm{~m}$ in height was formed by two kinds of gravel and its installation depth was varied. Table 1 shows the conditions of the filter layer. The installation depth is the distance from the beach surface. The coefficient of permeability is measured under a constant water head on the basis of Darcy’s law.

\begin{tabular}{|c|c|c|c|c|}
\hline \multicolumn{5}{|c|}{ Table 1. Conditions of grave for a filter layer } \\
\hline Filter & $\mathrm{D}_{50}(\mathrm{~mm})$ & Porosity & $\begin{array}{c}\text { Installation } \\
\text { depth(m) }\end{array}$ & $\begin{array}{c}\text { Permeabilty } \\
(\mathrm{cm} / \mathrm{s})\end{array}$ \\
\hline A & 3.4 & 0.38 & 0.1 & 0.27 \\
B & 3.4 & 0.38 & 0.05 & 0.15 \\
C & 16.5 & 0.4 & 0.05 & 0.1 \\
D & 16.5 & 0.4 & 0 & 0.13 \\
\hline
\end{tabular}

\subsection{Experimental procedure}

The Bretscheider-Mitsuyasu spectrum was used as the target spectrum of incident irregular waves. Depositional and erosive waves based on C parameters proposed by Horikawa et al. (1976) were generated for a couple of hours. The water depths were set to $0.4,0.35$ and $0.3 \mathrm{~m}$, and are referred to as

\footnotetext{
${ }^{1}$ Civil Engineering, Kobe City College of Technology, 8-3,Gakuen-Higashimachi,Nishiku,Kobe, $651-2194$ Japan,

${ }^{2}$ Civil Engineering, Nagaoka University of Technology,1603-1,Kamitomioka,Nagaoka,Niigata,940-2137,Japan
} 
the H.W.L. (high water level), M.W.L. (mean water level) and L.W.L. (low water level) respectively. Their initial shorelines correspond to the onshore side, the center and offshore side of the filter layer. Bottom profiles were measured at $2 \mathrm{~cm}$ intervals with a laser. Table 2 shows the regular wave (former experiments) and irregular wave conditions.

\begin{tabular}{|c|c|c|c|c|c|c|c|c|c|}
\hline & & & & e 2. Wal & nditions & & & & \\
\hline \multirow{3}{*}{ Case } & \multirow{3}{*}{$\begin{array}{l}\text { Depth } \\
(\mathrm{cm})\end{array}$} & \multicolumn{5}{|c|}{ Irregular waves } & \multicolumn{3}{|c|}{ Regular waves } \\
\hline & & \multicolumn{2}{|c|}{ Mean wave } & \multicolumn{2}{|c|}{ Significant wave } & \multirow[b]{2}{*}{ C } & \multicolumn{2}{|c|}{ Mean wave } & \multirow[b]{2}{*}{ C } \\
\hline & & $\begin{array}{l}\text { Height } \\
(\mathrm{cm})\end{array}$ & $\begin{array}{l}\text { Period } \\
\text { (s) }\end{array}$ & $\begin{array}{l}\text { Height } \\
(\mathrm{cm})\end{array}$ & $\begin{array}{c}\text { Period } \\
\text { (s) }\end{array}$ & & $\begin{array}{l}\text { Height } \\
(\mathrm{cm})\end{array}$ & $\begin{array}{l}\text { Period } \\
\text { (s) }\end{array}$ & \\
\hline 1 & 40 & 2.1 & 1 & 3.4 & 1.13 & 2.3 & 3.8 & 1.1 & 2.5 \\
\hline 2 & 40 & 7.3 & 1.25 & 11.6 & 1.41 & 6.7 & 13.3 & 1.23 & 8.1 \\
\hline 3 & 35 & 2.1 & 1 & 3.3 & 1.14 & 2.2 & 2.6 & 1.1 & 1.7 \\
\hline 4 & 35 & 6.7 & 1.19 & 10.6 & 1.36 & 6.4 & 12.4 & 1.23 & 7.6 \\
\hline 5 & 30 & 2 & 1 & 3.1 & 1.08 & 2.2 & 3.1 & 1.1 & 2 \\
\hline 6 & 30 & 7.1 & 1.24 & 10.5 & 1.39 & 6.2 & 11.3 & 1.23 & 6.9 \\
\hline
\end{tabular}

To measure the sand grain size and coefficient of sorting, pictures of the bed surface were taken with a digital camera at $10 \mathrm{~cm}$ intervals in the onshore-offshore direction. This method was developed by Rubin (2004) and does not disturb the beach profile; therefore, it is particularly useful for tracking changes in sand grain size.

\subsection{Grain size analysis using digital images}

On the basis of spatial autocorrelation, Rubin (2004) proposed a new method of estimating grain sizes. Spatial autocorrelation can be defined as the correlation between two rectangular regions in a sand grain image, measured by calculating the correlation between the intensity of each pixel in one image with the pixel in the corresponding location in the second image. Calculating the spatial correlation at a variety of offsets-distances between the two images-produces a curve that describes the correlation as a function of distance. This curve is known as a correlogram. The grain diameter can be determined by matching the correlogram of the sample against the correlogram of the calibrated samples. Tsujimoto et al. (2008) confirmed the validity of this method.

\section{Experimental results for only depositional or erosive waves}

\subsection{Bottom profiles}

Figures 1, 2 and 3 show bottom profiles for depositional and erosive irregular waves at the H.W.L., M.W.L. and L.W.L. after 1.5 hours of wave action, respectively. As shown in Fig.1, the shoreline develops regardless of the type of filter layer. The scale of the beach berm and height of the offshore bar that form under irregular waves are smaller than those that form under a regular wave. In addition,

the offshore bar has

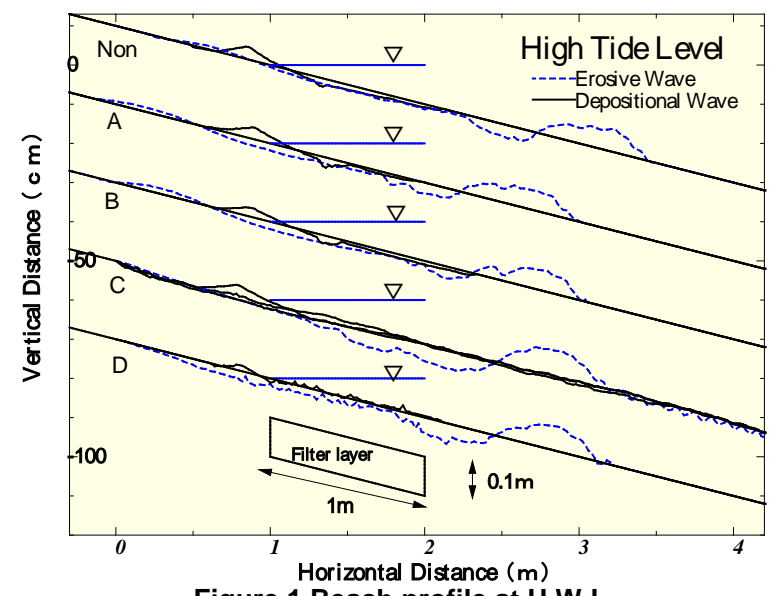

Figure 1 Beach profile at H.W.L.

a wider crown and is forms more landward. This is the reason that the wave breaking point, differing from the case for the regular wave. The sediments are deposited over the swash zone under the action of erosive waves which has not been seen under the action of regular waves. The region near the initial shoreline is eroded for 
all types of filter layer and its scale is almost the same. The gravel for type $\mathrm{C}$ is exposed to the bed surface.

Figure 2 shows the results for the M.W.L. The berm formation for type D, comparing with other types of filter layer, is not clear. The bed surface for type D includes gravel grains, and fine sand grains are often picked up from the gravel at the surface under swash action. As a result, only gravel grains remain and the surface becomes rough. Therefore, the rate of sediment transport is reduced and the berm does not develop. With the coefficient of permeability increasing, the sediment deposits over the foreshore side even under the action of erosive waves. As a results, the amount of sediment transported toward the offshore side is reduced and the scale of the bar and trough are smaller.

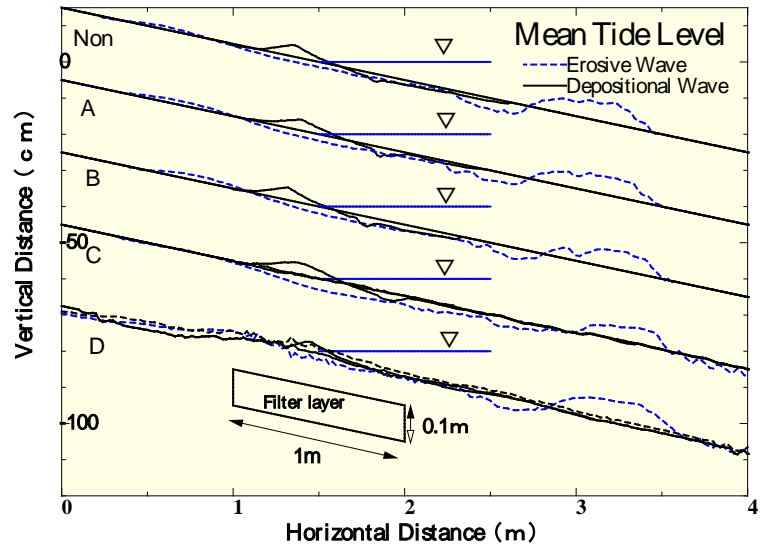

Figure 2 Beach profile at M.W.L..

Figure 3 shows the results for the L.W.L. The berm and offshore bar for filter-layer types A and B form more landward than those for types $C$ and $D$. The swash zone is always over the filter layer for the L.W.L., and the permeability of filter-layer types A and B is greater than that of filter-layer types C and D. Therefore, permeability has much more influence on the beach profile.

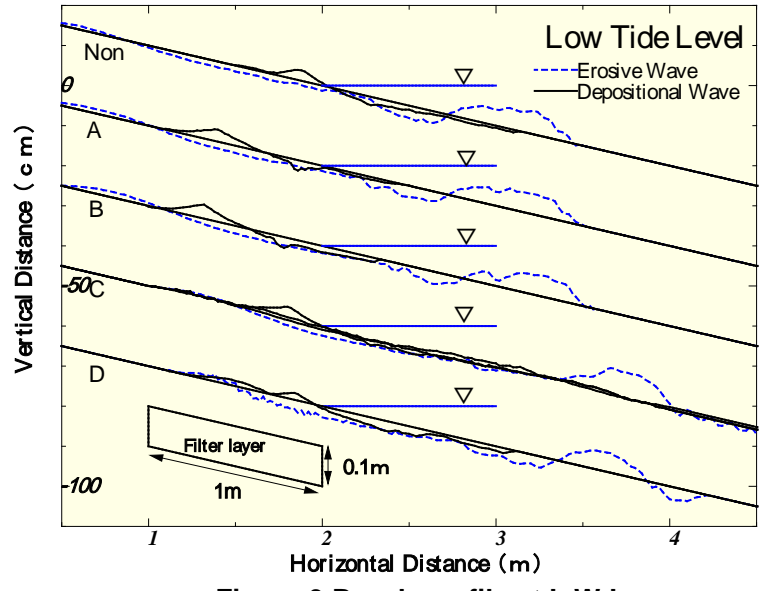

Figure 3 Beach profile at L.W.L..

\subsection{Profile of a berm}

Figure 4 shows the berm height and distance between the shoreline and run-up point in descending order of permeability. In addition, the values estimated by Takeda and Hunt are plotted. As expressed by Nish et al. (1988), the rates of sediment transport under irregular wave action are a little smaller that those under regular wave action. Hence, the beach profile changes under irregular wave action are a little smaller than those under regular wave action. As shown in Fig.3, the differences in the run-up point and berm height are remarkable, especially for the L.W.L. The experimental results are smaller than the estimated values. 
3.3 Slope of the wave number spectrum of the beach profile

The characteristics of the beach profile were analyzed on the basis of the wave number spectra in the former paper. The same approach is applied here. It is generally said that the " -3 power law" for the spatial spectrum of sand waves in the equilibrium range is satisfied. Figure 5 shows the slopes of the wave number spectra in descending order of permeability. With increasing permeability, the beach profile enters the equilibrium range. Since the surface roughness resulting from sorting increases for type $\mathrm{D}$, the beach profile cannot affect the equilibrium range.
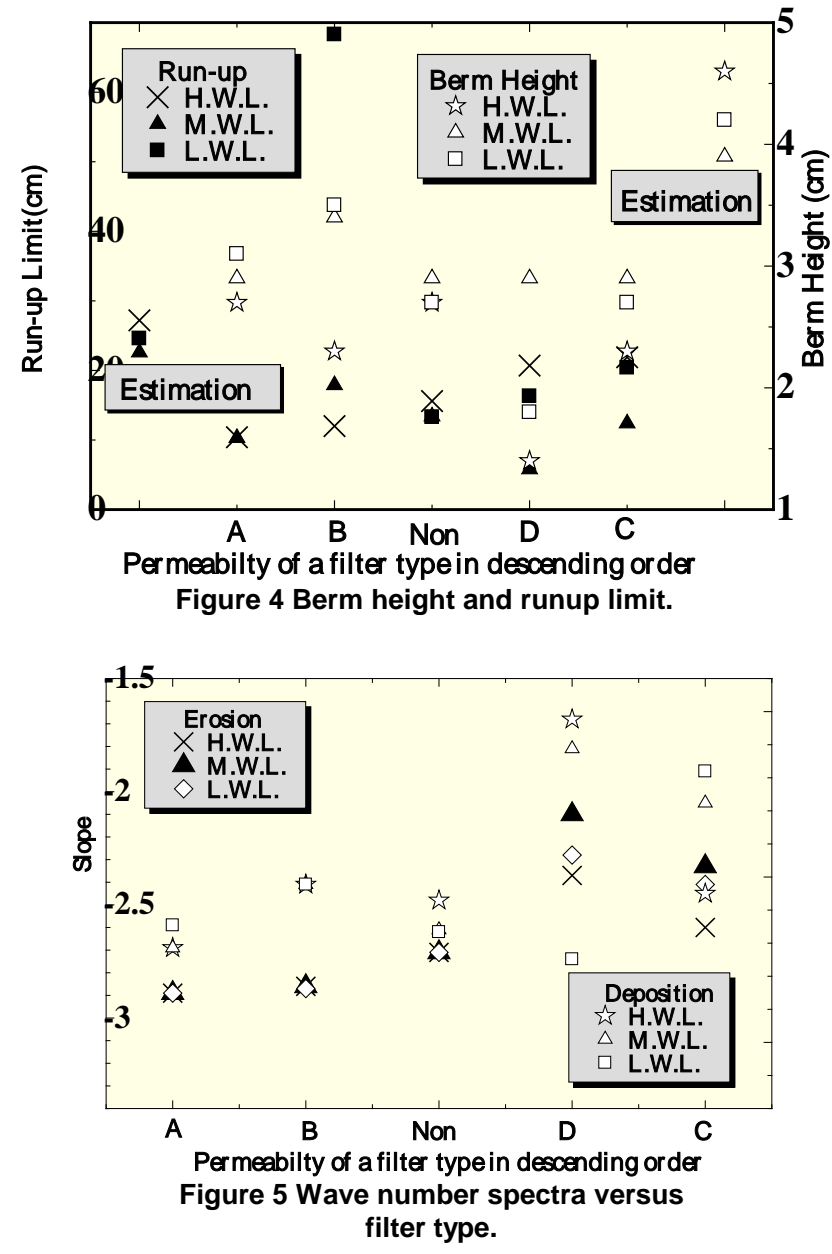

\section{Experimental results for both erosive and depositional waves}

4.1 Invertibility from the viewpoint of the beach profile

Experiments on invertibility were conducted on the basis of the safety of the beach profile as in the former paper. The definition of invertibility is that the offshore bar and trough that form under erosive wave action disappear under depositional wave action. Depositional waves are generated for 2 hours after the action of erosive waves for 45 minutes. Whether the beach profile reaches becomes the state of equilibrium in only two hours is not clear, but focusing on the effect of filter layer. Figure 6 shows the results for the M.W.L. There are no remarkable disappearances of troughs and bars with and without a filter layer, indicating there is no invertibility. Depositional waves are then generated for the L.W.L. and the results are shown in Fig. 7. The disappearance of bars and sediment deposition into the trough are more apparent than in the case of the M.W.L., indicating invertibility. 


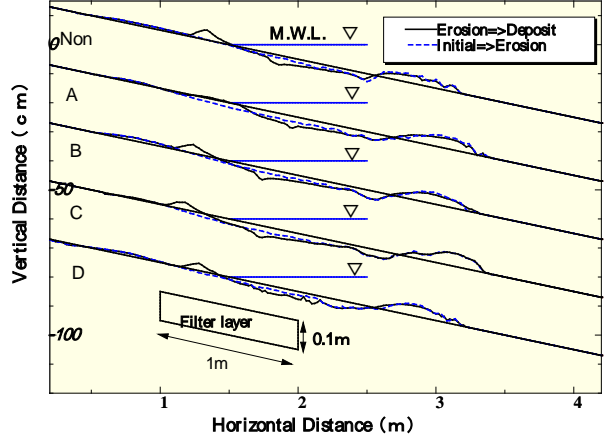

Figure 6 Process of beach profile change (M.W.L.).

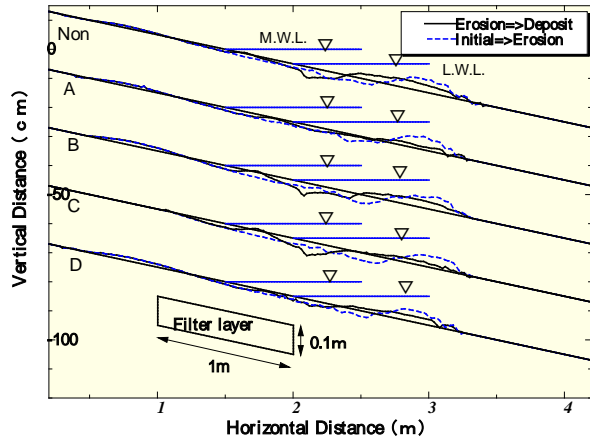

Figure 7 Process of beach profile change (L.W.L.).

4.2 Invertibility in terms of sediment grain size

As shown in Fig. 6, there is no clear invertibility of the beach profile regardless of the presence of a filter layer for the M.W.L. In the depositional beach profile, the sediment grain size around a berm becomes coarse with the development of berm height. Tsujimoto et al. (2008) showed that the variation in sediment grain size at a depositional beach surface was different from that an erosive beach surface.

To examine invertibility in terms of the sediment grain size, the distribution of sediment grain size is shown in Fig. 8. Since it is difficult to make the same initial bed profile for all filter types, the values of sediment grain size differ. However, the distribution profiles of sediment grain size are similar; coarse grain sediments over $0.5 \mathrm{~mm}$ in diameter are deposited around the bar and fine sediments under $0.5 \mathrm{~mm}$ in diameter are deposited close to the run-up limit. After the depositional wave action, the sediment grain size close to the shoreline changed from 0.5 to $1.0 \mathrm{~mm}$ and the group of coarse particles is found at the top of the berm and at the plunge point; there are two peak points across a beach.

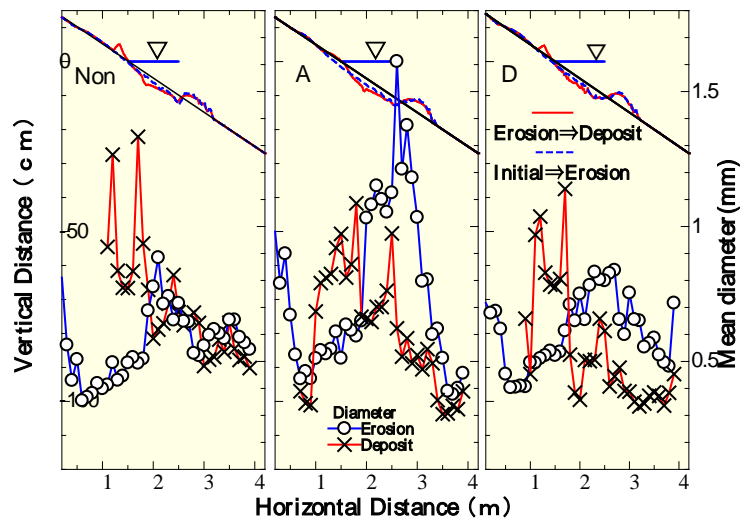

Figure 8 Grain size at bed surface and beach profile.

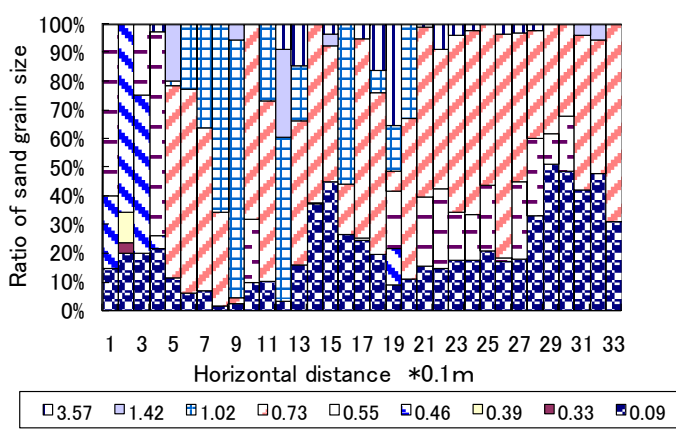

Figure 9 Ratio of the sand grain size at the bed surface. 
There are few differences among the profiles of the offshore bar. However, the sediment grain size changes from 1.0 to $0.5 \mathrm{~mm}$ after depositional wave action with a filter layer. Hence, the variation in sediment grain size can be an index for estimating invertibility. Figure 9 shows the ratio of the sediment grain size corresponding to filter type A in Fig. 8. The sediments become more coarse from the offshore side to onshore side.

\section{Numerical approach}

\subsection{Basic equation}

As shown in Fig. 10, the flow fields can be classified into two groups: a water flow region and permeable flow region. The dashed line in the figure indicates the edge of the permeable layer and the solid line indicates the bed surface. Following (Asano, 1999), the modified Boussinesq equation based on the non-linear long wave equation and the continuous equation were applied to both regions.

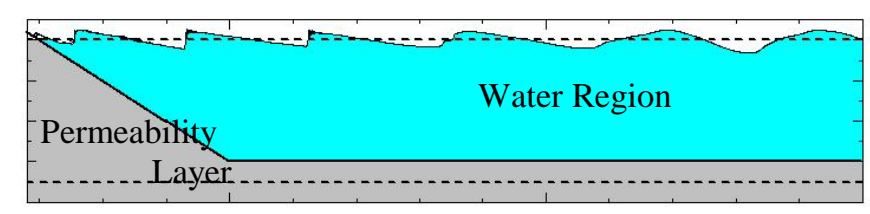

Figure 10 Schematic diagram of the calculation region.

The basic equations are as follows;

$$
\begin{aligned}
& \frac{\partial d}{\partial t}+\frac{\partial}{\partial x}(u d)=-q_{b} \\
& \frac{\partial}{\partial t}(u d)+\frac{\partial}{\partial x}\left(u^{2} d\right)+g d \frac{\partial \eta}{\partial x}-v \frac{\partial^{2}}{\partial x^{2}}(u d)=-\frac{1}{2} f|u| u \\
& -u_{b} q_{b}+\left(B+\frac{1}{3}\right) h^{2} \frac{\partial^{3}}{\partial x^{2} \partial t}(u d)+B g h^{3} \frac{\partial^{3} d}{\partial x^{3}} \\
& \frac{\partial}{\partial x}\left(h_{p} u_{p}\right)=q_{b} \\
& \frac{\partial}{\partial t}\left(h_{p} u_{p}\right)+\frac{1}{n_{p}} \frac{\partial}{\partial x}\left(h_{p} u_{p}^{2}\right)-u q_{b}=-g n_{p} h_{p} \frac{\partial \eta}{\partial x}-R
\end{aligned}
$$

Here $d=h+\eta$ is the instantaneous total depth, $\eta$ is the surface elevation from the free water surface, $h$ is the still water depth, $u$ is the instantaneous depth-averaged velocity, $q_{b}$ is the flux, $f$ is the friction factor, $h_{p}$ is the permeable layer depth, $u_{p}$ is the instantaneous depth-averaged velocity in the permeable layer, $n_{p}$ is the porosity and $\mathrm{R}$ is the resistance coefficient. The instantaneous depthaveraged velocity $u_{p}$ is classified into two parts.

$$
\begin{array}{llrl}
u_{b} & =u & \text { for } & q_{b}>0 \\
u_{b}=u_{p} / n_{p} & \text { for } & q_{b}<0
\end{array}
$$

Since the filter layer is installed only near the bed surface, the coefficient of permeability changes in the vertical direction. However, the values given in Table 1 are used for the calculation cells where the filter layer is installed. Using the incident wave conditions given in Table 2, the number of calculation cell is 3500 , the cell size is $0.005 \mathrm{~m}$ and the time step is $0.001 \mathrm{~s}$.

\subsection{Calculation results}

Figure 11 illustrates the calculation water elevation and velocities for filter types A, C and D under case 1 of the wave condition. The water elevation and velocities over a filter layer differ depending on the filter type; the permeability has an effect on the flow field. This is much more remarkable in the phase of run-down flow than in the phase of run-up flow. Because the boundary condition of the water 
elevation in the permeable layer to boundary conditions is incorrect, there are small variations in the velocity over the swash zone.
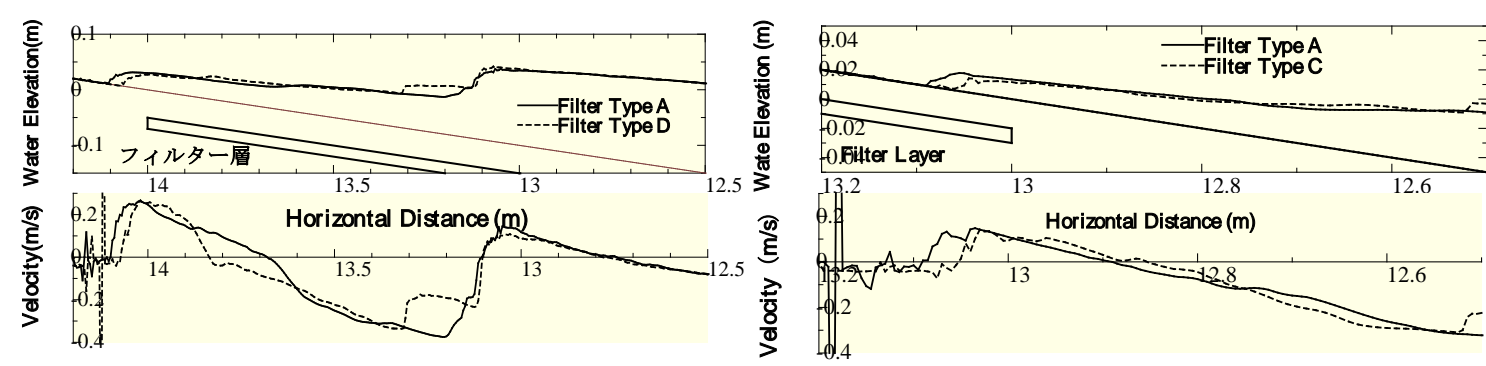

Figure 11 Calculation results.

\section{Conclusions}

From the viewpoint of the safety of coastal beaches under irregular wave action, the following conclusions were obtained.

(1)The swash zone under irregular wave action is wider than that under regular wave action. Therefore, a filter layer promotes the deposition of sediment near the top of the run-up under even erosive wave action with increasing permeability of the filter layer.

(2) By setting the onshore edge of a filter layer in the position of the shoreline at the H.W.L., the above- mentioned process is further promoted.

(3) Invertibility of beach profiles is low without changes in the tide level as well as under regular wave action. However, invertibility is promoted by changing the tide level and the stability of beach profiles is not hindered.

(4) It is possible to judge the invertibility of a beach profile from the distribution of the grain size.

\section{ACKNOWLEDGMENTS}

This study is partially supported by a Grant in Aid for Science Research from the Ministry of Education, Culture, Sports, Science and Technology, Japan.

\section{REFERENCES}

Asano T.1999.Wave action near the swash zone, Summer Seminar, JSCE, B-6-1-17. (in Japanese)

Horikawa,K.,T.Sunamura and H.Kondo. 1976. Experiments on two dimensional beach profile changes due to wave actions, Annual Journal of Coastal Eng., JSCE, 23,193-200. (in Japanese)

Nishi I., M. Sato,K.Matano, S.Makino and H. Yasui,1988. Experiments on beach profile changes under irregular waves, Annual Journal of Coastal Eng., JSCE, 35,426-466. (in Japanese)

Tsujimoto G., T.Hosoyamada, T.Ohnishi and T.Kakinoki , 2007. Beach profile change of an artificial coast with a gravel filter layer, Coastal Structure 07, 571-582.

Tsujimoto G., F.Yamada and T.Kakinoki, 2008. A study on measuring sand particle size using digital images of sediment by Rubin's method, Annual Journal of Civil Engineering in the Ocean, JSCE, 36, 464-468. (in Japanese)

Uda T., A. Omata andT. Takebuchi. 1989. Time and spatial variation of sediment grain size and mechanism of berm at the foreshore side, Annual Journal of Coastal Eng., JSCE, 36,359-363. (in Japanese)

Barnard Patrick L., David M.Rubin, Jodi Harney and Neomi Mustain 2007.Field test comparioson of an autocorrelation technique for determining gain size using a digital 'beachball'camera versus traditional methods, Sedimentary Geology, 201, 180-195

Kobayashi, N. and Q. Wurjanto 1990, Numerical model for waves and on rough permeable slopes, Journal of Coastal Research, 149-166.

Rubin David M. 2004. A simple autocorrelation algorithm for determining grain size from digital images of sediment, Journal of Sedimentary Research, 74, No.1, 160-165 